\title{
The Effects of Weekly Recreational Soccer Intervention on the Physical Fitness Level of Sedentary Young Men
}

\author{
Alper Aslan ${ }^{1}$, Yasar Salci ${ }^{1}$, Alpay Guvenc ${ }^{2}$
}

Affiliations: 'Hatay Mustafa Kemal University, School of Physical Education and Sports, Coaching Education, Hatay, Turkey, ${ }^{2}$ Antalya Akdeniz University, Faculty of Sports Sciences, Coaching Education, Antalya, Turkey

Correspondence: A. Aslan, Hatay Mustafa Kemal University, School of Physical Education and Sports, Coaching Education, Akıncılar, 31001 Alahan/Antakya/Hatay, Turkey. E-mail: alperaslan72@gmail.com

ABSTRACT Recreational soccer (RS) has a great potential to improve the physical fitness levels of diverse populations when performed two to three times per week. However, to date, only Beato and collaborators have examined the effects of once-a-week RS on physical fitness, even though this frequency is widespread among participants. Thus, this study aimed to investigate the effect of weekly performed RS intervention on components of physical fitness in sedentary young men. Twenty-healthy men aged 20-27 years were randomly assigned to a soccer $(n=10)$ group or a control $(n=10)$ group. Participants in the soccer group played a 60-min. small-sided soccer game once-a-week for eight weeks. Before and after the intervention period, body composition, aerobic fitness, blood pressure, anaerobic performance and isokinetic leg strength were assessed. After eight weeks of the once-a-week intervention period, in the soccer group, body fat and thickness of skinfolds were significantly decreased $(\mathrm{p}<0.05)$. Peak oxygen uptake, running distance, squat and countermovement jump $(\mathrm{p}<0.01)$, concentric quadriceps and eccentric hamstring strength were also improved only in the soccer group $(\mathrm{p}<0.05)$. In contrast, other variables, including body mass $(\mathrm{BM})$, body mass index (BMI), fat-free mass (FFM), heart rate responses, blood pressure, and anaerobic performance remained the same as before the intervention period ( $\mathrm{p}>0.05)$. Participating in weekly RS programme can lead to some health and performance benefits. However, the people who wish to further improve their health status and performance level should increase the frequency of RS activity.

KEY WORDS health, body composition, aerobic endurance, strength, heart rate

$@$ MJSSMontenegro

EFFECTS OF WEEKLY RECREATIONAL SOCCER INTERVENTION

http://mjssm.me/?sekcija=article\&artid=173

\section{Introduction}

It is well established that physical activity is related to decreased risk of several chronic diseases, improved physical capacity, and increased quality of life. Therefore, physicians focus on promoting regular physical activity habits that will be retained throughout the lifespans of their patients. In this context, RS has a great potential to improve the health and physical fitness levels of diverse populations. This may because the dynamic nature of soccer not only provides opportunities to develop different aspects of physical fitness of participants, but it also contains positive motivational and social factors that contribute to the maintenance of a physically active lifestyle (Andersen et al., 2010).

Multiple studies of diverse populations have demonstrated that average cardiovascular load during RS exceeded $80 \%$ heart rate (HR) maximum even in elderly individuals (Randers et al., 2010b; Randers et al., 2012; Aslan, 2013). Moreover, a recent study demonstrated that during RS 20-30\% of total time spend with an HR above $90 \%$ of the maximal HR (Randers et al., 2010b). Furthermore, RS is an intermittent activity including many high-intensity actions (sprinting, turns, jumping, kicking, accelerations, and decelerations) the would be expected to stimulate positive adaptations in several physical fitness parameters. However, the number of training sessions or weekly training volume and the length of the intervention period are also the most 
vital components to achieve morphological and physiological adaptations. In recent studies, it was demonstrated that 12 weeks of soccer practice performed three 60 min sessions per week improved maximal aerobic power, jumping performance, flexibility, and body composition parameters in healthy untrained young males (Milanovic, Pantelic, Kostic, Trajkovic, \& Sporis, 2015b; Milanovic, Pantelic, Sporis, Mohr, \& Krustrup, 2015c).

Similarly, Randers et al. (2012) demonstrated that 12 weeks of soccer games three days per week increased the physical fitness level and cardiovascular health status of middle-aged homeless men, represented by $\mathrm{VO}_{2} \max$, incremental cycle test performance, fat percentage, and LDL cholesterol. Krustrup et al. (2010a) also reported similar findings in a study of untrained men when the small-sided RS was performed two to three times per week for 12 weeks. There is also experimental evidence for the effectiveness of RS in the improvement of the physical fitness of different population groups, including premenopausal women (Krustrup et al.,2010b) mild to moderate hypertensive middle-aged men (Andersen et al., 2010) and prepubertal children (Krustrup et al., 2014) when the activity was performed two to three days a week.

In contrast, a lack of time is one of the most commonly reported barriers to exercise participation (Gibala, Little, MacDonald, \& Hawley, 2012). Therefore, this may be the reason that a single RS session a week is as common or even more common among participants. A recent study demonstrated that a single RS session a week accounted for 50\% of the ACSM-recommended lowest level of energy expenditure (Beato, Impellizzeri, Coratella, \& Schena, 2016). However, to our knowledge, there is only one study investigating the effect of a single RS session a week on physical fitness levels (Beato, Coratella, Schena, \& Impellizzeri, 2017) and there is still a great deal of uncertainty about the threshold activity levels that can enhance health and performance level of young individuals (Hiruntrakul, Nanagara, Emasithi, \& Borer, 2010). The time-efficient threshold theory proposes that intensity coupled with minimal frequency and duration of training may provide the requisite stimulus (Winett \& Carpinelli, 2000). Therefore, the purpose of this study was to investigate the effects of weekly performed RS intervention on the components of physical fitness in young sedentary males.

\section{Methods}

Participants and Procedure

Twenty sedentary healthy men not previously involved in any systematic training participated in this study. Participants were randomly assigned either to a soccer group [ $\mathrm{n}=10$, age $22.1 \pm 1.8$ years, height $172.6 \pm 4.4 \mathrm{~cm}$, BM $70.8 \pm 3.9 \mathrm{~kg}$ ] or to a control group [ $\mathrm{n}=10$, age $23.4 \pm 1.6$ years, height $173.9 \pm 4.7 \mathrm{~cm}, \mathrm{BM} 72.4 \pm 4.7 \mathrm{~kg}$ ]. Participants in the soccer group played a one-hour small-sided soccer game once-a-week for eight weeks on a 30-50-metre artificial grass pitch (excluding goalkeepers, each team comprised five players), whereas participants in the control group continued their routine daily life. During the games, HR responses were recorded with a sampling frequency of $5 \mathrm{~s}$ using a Polar HR monitor (RS800 CX, Polar Electro, Finland) to determine the game intensity throughout the intervention period. Then intensity was quantified as the mean percentage of HR reserve (\%HRres). \%HRres was calculated according to the formula of Karvonen (1957). [(\%HRres=(match mean HR-resting HR)/(HRmax-resting HR)x100]. Before and after the eight weeks of intervention, the following tests were administered to all participants on separate days in the following order: I) resting HR, systolic blood pressure (SBP) and diastolic blood pressures (DBP), anthropometric measurements, squat jump (SJ) and countermovement jump (CMJ) tests, II) Wingate anaerobic test (WAnT), III) isokinetic leg strength test, IV) the maximal multistage 20 -m shuttle run test (SRT). The last three tests were conducted at least one day apart from each other to allow for adequate recovery. All of these tests were completed within the one-week period in the same order, before the beginning of the intervention (pre-test) and after the completion of the eight weeks intervention period (post-test). All tests were conducted under indoor conditions at the same time of day, and the participants were familiar with these test procedures before actual testing. All subjects were instructed to abstain from eating for at least two hours before the tests. In addition, they were asked to maintain their nutritional habits and daily lifestyle throughout the intervention protocol. The average temperature and humidity during the pre-test were $18.2 \pm 1.7^{\circ} \mathrm{C}$ and $63.7 \pm 4.18 \%$, respectively (Hanna Instruments, $\mathrm{HI} 8564$, Italy). Corresponding values during the post-test were $21.3 \pm 1.3^{\circ} \mathrm{C}$ and $67.1 \pm 2.57 \%$, respectively. The study received ethical approval from the human ethics committee of local university (2013/07), and informed consent was obtained from all participants.

\section{Anthropometric Measurements}

Height and BM were measured using a calibrated electronic scale (Seca, France) to the nearest $0.1 \mathrm{~cm}$ and $0.1 \mathrm{~kg}$, respectively, with the subject lightly dressed without shoes. BMI was calculated as BM $(\mathrm{kg})$ divided by height $\left(\mathrm{m}^{2}\right)$. The thickness of eight skinfolds (biceps, triceps, subscapular, chest, suprailiac, abdominal, thigh and medial calf) was measured with a skinfold calliper (Holtain Ltd, UK) to the nearest $0.2 \mathrm{~mm}$, on the right side of the body, using standard procedures (Lohman \& Roche, 1988). The sum of the eight skinfolds was used as a total indicator of fatness. Alternatively, the sums of arm, trunk, and leg skinfolds were also used as a regional indicator of fatness. Moreover, the percentage of body fat (\%BF) was calculated from the Faulkner equation (Faulkner, 1968). Fat-free mass (FFM) was calculated from \%BF and BM. One investigator performed all measurements to avoid any inter-observer differences. 
Determination of Resting Heart Rate and Blood Pressures

Resting HR was recorded for 10 minutes in a supine position using HR monitor (RS800 CX, Polar Electro, Finland). Thereafter, the minimum HR observed during this period was used as the resting HR value (Dellal et al., 2012). SBP and DBP were measured three times on the left arm at the level of the heart (Omron Healthcare Co. Ltd, Kyoto, Japan). All the measurements were completed in the morning at 8:00-10:00 am. The SBP and DBP were determined as the average of three recordings in $\mathrm{mmHg}$. The mean arterial blood pressure (MAP) was calculated by the following formula: [(SBP-DBP)/3+DBP] (Elliott, Sale, \& Cable, 2002).

\section{Squat and Counter Movement Jump Tests}

Before the tests, each subject performed a standardized warm-up protocol. SJ and CMJ performances were measured using an electronic timing mat (Ergo Tester, Italy). SJ was performed from a half squatting position with hands placed on hips. The participants were asked to remain motionless for $2 \mathrm{~s}$, and then they jumped vertically for maximal height. The participants were not allowed to countermovement at the start of the jump. CMJ was administered while the participants started from an erect standing position. Then, they made a downward countermovement to the same starting position as the SJ and jumped vertically for maximum height. All participants performed three consecutive trials, and the highest value for each jump was used.

\section{Wingate Anaerobic Test}

The WAnT was performed on a computerized cycle-ergometer (Monark 834E, Sweden). Before the test, each subject was informed about the protocol. The seat height was adjusted for each subject, and the feet were strapped to the pedals. After a standardized 3-min warm-up, the subject rested for 5 min (Inbar, Bar-Or, \& Skinner, 1996). The subject was instructed to perform the test as fast as possible. Then the WAnT was initiated against minimal resistance. Following 3-4 seconds, the predetermined resistance $\left(75 \mathrm{gr}^{-\mathrm{kg}^{-1}}\right)$ was applied, and the computer was activated. Verbal encouragement was given throughout the 30 -s test. After the test, the subject was instructed to pedal slowly to assist recovery. The highest and the lowest power output obtained in the 30-s were defined as peak and minimum power, respectively, and the mean power was the average of all values obtained during the test. A fatigue index was also calculated (Inbar et al., 1996). Power outputs were expressed in absolute (W) and relative units $\left(\mathrm{W} \cdot \mathrm{kg}^{-1}\right)$.

\section{Isokinetic Leg Strength Test}

Isokinetic strength data were recorded with the Biodex System-4 Dynamometer (Biodex Medical Inc, Shirley, NY) to assess the strength of the muscle groups in accordance with the Biodex System manual (Biodex MultiJoint System Pro, 2017). Strength measurements were preceded by a five-minute standardized warm-up on a cycle ergometer at $80 \mathrm{~W}$. Each subject then performed lower extremity flexibility exercises, including quadriceps, hamstring, and calf stretches. Every stretching exercise was performed three times and held for $15 \mathrm{~s}$. Subjects were tested for both concentric and eccentric quadriceps $\left(\mathrm{Q}_{\mathrm{con}} \& \mathrm{Q}_{\mathrm{ecc}}\right)$ and hamstring $\left(\mathrm{H}_{\text {con }} \& \mathrm{H}_{\text {ecc }}\right)$ strength on dominant legs at $60 \%$ s. The dominant leg was defined as the preferred kicking leg. The testing criteria consisted of three maximal concentric and eccentric efforts; meanwhile, three submaximal knee extension and flexion contractions were allowed before the real tests. A 3 min. rest was allowed for between each test. Peak torque (PT), PT to body weight (PT/BW), conventional $\left(\mathrm{H}_{\text {con }} / \mathrm{Q}_{\text {con }}\right)$ and dynamic control $\left(\mathrm{H}_{\text {ecc }} / \mathrm{Q}_{\text {con }}\right)$ ratios were chosen for strength analysis.

\section{Maximal Multistage 20-m Shuttle Run Test}

Aerobic fitness was assessed using SRT according to the one-min protocol (Leger, Mercier, Gadoury, \& Lambert, 1998). During the SRT, HR was recorded continuously every 5-s period with a Polar HR monitoring system. Peak HR was determined for each subject as the highest HR recorded during any 5-s period of the SRT. Moreover, HR responses to submaximal running speeds were also calculated for each subject. At the end of the SRT, the total number of completed shuttles was recorded for each subject. Thereafter, the peak oxygen uptake $\left(\mathrm{VO}_{2}\right.$ peak $)$ was calculated from the following formula: $\left[\mathrm{VO}_{2}\right.$ peak $=61.1-(0.462 \times$ age $)-(0.862 \mathrm{x}$ $\mathrm{BMI})+(0.192 \times$ number of shuttles completed)] (Matsuzaka et al., 2004). In addition, peak running distance (RDpeak) (i.e., number of completed shuttles multiplied by 20-m) during the SRT was also calculated for each subject and used in the further analysis.

\section{Statistical Analysis}

All data were presented as mean value \pm standard deviation (sd). The assumption of normality and homogeneity of variance were verified using the Kolmogorov-Smirnov and Hartley's $\mathrm{F}_{\max }$ test, respectively. The data were analyzed with separate $2 \times 2$ (groups and time) mixed repeated-measures ANOVA design. The SPSS's syntax language was used to analyse the simple effect of time within levels of group variable. All statistical analysis was performed using SPSS for Windows, version 15.0 (SPSS Inc., Chicago, USA). The level of statistical significance was set at $\mathrm{p}<0.05$ for all analyses.

Results

The mean intensity of the soccer small-sided games was $172.7 \pm 1.9 \mathrm{~b} \cdot \mathrm{min}^{-1}$ (within the range of 169.6 to175.1 b. $\min ^{-1}$ ), which corresponded to $80.6 \pm 4.3 \%$ of the HRres (Figure 1). 


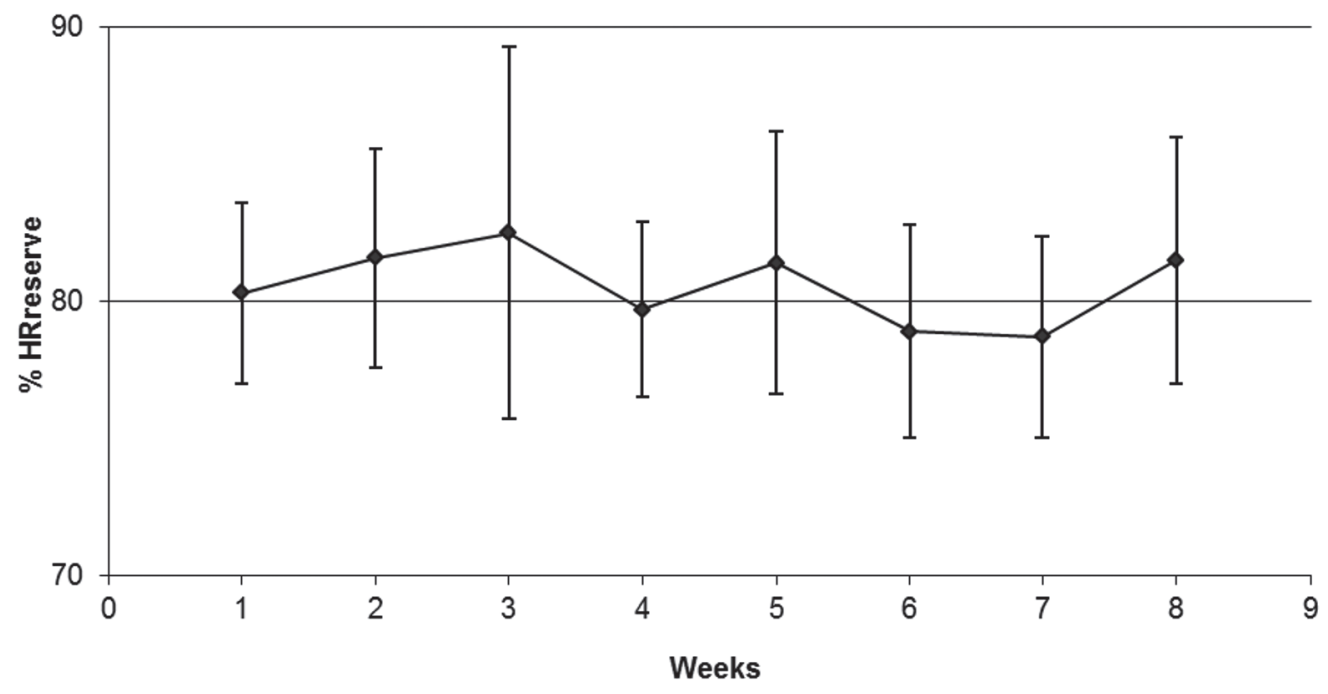

FIGURE 1 Game intensity throughout the 8-weeks of intervention period

There was no significant difference in all parameters between the soccer and the control group before the intervention period (Table 1 and Table 2). After the weekly intervention period, $\% B F\left(F_{1,18}=4.784, p<0.05\right)$, the sum of eight skinfolds $\left(\mathrm{F}_{1,18}=4.667, \mathrm{p}<0.05\right)$ and arm skinfolds $\left(\mathrm{F}_{1,18}=8.742, \mathrm{p}<0.01\right)$ were significantly reduced in the soccer group, but unchanged in the control group (Table 1). Moreover, BM, BMI, FFM, sum of the trunk and leg skinfolds, resting HR and MAP values also tended to reduce after the intervention period in the soccer group, but the differences were not statistically significant $(\mathrm{p}>0.05)$ (Table 1$)$.

TABLE 1 Body composition, blood pressures, heart rate and aerobic endurance variables before and after the 8 weeks of weekly intervention in the soccer and control groups. Data are presented as means $\pm \mathrm{sd}$

\begin{tabular}{lcccc} 
& \multicolumn{2}{c}{ Soccer Group } & \multicolumn{2}{c}{ Control Group } \\
\cline { 2 - 5 } & Pre-test & Post-test & Pre-test & Post-test \\
\hline Body mass $(\mathrm{kg})$ & $70.8 \pm 3.9$ & $69.8 \pm 4.4$ & $72.4 \pm 4.7$ & $73.1 \pm 5.5$ \\
BMI $\left(\mathrm{kg} / \mathrm{m}^{2}\right)$ & $23.8 \pm 1.3$ & $23.4 \pm 1.4$ & $24.0 \pm 1.5$ & $24.2 \pm 1.7$ \\
Body fat $(\%)$ & $13.2 \pm 2.1$ & $12.5 \pm 1.9^{*}$ & $12.7 \pm 2.3$ & $12.5 \pm 2.4$ \\
FFM $(\mathrm{kg})$ & $61.4 \pm 2.3$ & $61.0 \pm 2.9$ & $63.2 \pm 3.2$ & $63.8 \pm 3.6$ \\
$\Sigma \mathrm{S}(\mathrm{mm})$ & $81.4 \pm 19.4$ & $74.8 \pm 18.4^{*}$ & $79.7 \pm 24.5$ & $78.5 \pm 27.6$ \\
Trunk $\Sigma \mathrm{S}(\mathrm{mm})$ & $50.4 \pm 15.5$ & $46.3 \pm 14.2$ & $47.0 \pm 16.0$ & $45.8 \pm 17.3$ \\
Arm $\Sigma \mathrm{S}(\mathrm{mm})$ & $12.6 \pm 2.2$ & $11.2 \pm 2.2^{* *}$ & $12.2 \pm 3.1$ & $12.4 \pm 4.3$ \\
Leg $\Sigma \mathrm{S}(\mathrm{mm})$ & $18.4 \pm 4.5$ & $17.3 \pm 4.1$ & $20.5 \pm 6.8$ & $20.3 \pm 7.8$ \\
DBP $(\mathrm{mmHg})$ & $75.0 \pm 2.9$ & $73.6 \pm 3.2$ & $73.8 \pm 3.1$ & $72.8 \pm 3.7$ \\
SBP $(\mathrm{mmHg})$ & $118.7 \pm 7.4$ & $116.4 \pm 7.9$ & $116.6 \pm 7.3$ & $114.1 \pm 6.8$ \\
MAP $(\mathrm{mmHg})$ & $89.6 \pm 3.1$ & $85.7 \pm 2.4$ & $88.1 \pm 4.3$ & $86.5 \pm 3.5$ \\
Resting HR $\left(\mathrm{b} \cdot \mathrm{min}^{-1}\right)$ & $66.0 \pm 6.2$ & $64.2 \pm 5.9$ & $65.7 \pm 6.5$ & $66.50 \pm 7.3$ \\
HR at $9 \mathrm{~km} \cdot \mathrm{h}^{-1}\left(\mathrm{~b} \cdot \mathrm{min}^{-1}\right)$ & $161.4 \pm 6.6$ & $158.2 \pm 5.7$ & $164.7 \pm 5.8$ & $162.9 \pm 4.8$ \\
HR at $10 \mathrm{~km} \cdot \mathrm{h}^{-1}\left(\mathrm{~b} \cdot \mathrm{min}^{-1}\right)$ & $177.0 \pm 5.5$ & $173.8 \pm 2.3$ & $175.6 \pm 5.6$ & $176.3 \pm 5.4$ \\
HR at $11 \mathrm{~km} \cdot \mathrm{h}^{-1}\left(\mathrm{~b} \cdot \mathrm{min}^{-1}\right)$ & $186.2 \pm 6.3$ & $183.6 \pm 3.8$ & $184.2 \pm 4.5$ & $184.9 \pm 5.5$ \\
HR at $12 \mathrm{~km} \cdot \mathrm{h}^{-1}\left(\mathrm{~b} \cdot \mathrm{min}^{-1}\right)$ & $193.4 \pm 5.3$ & $191.9 \pm 5.4$ & $190.3 \pm 4.3$ & $191.1 \pm 4.6$ \\
HRpeak $\left(\mathrm{b} \cdot \mathrm{min}^{-1}\right)$ & $199.2 \pm 3.7$ & $199.5 \pm 4.9$ & $198.5 \pm 2.8$ & $198.2 \pm 4.3$ \\
RDpeak $(\mathrm{m})$ & $1757.8 \pm 108.4$ & $2046.7 \pm 162.5^{*}$ & $1772.0 \pm 253.4$ & $1812.0 \pm 232.5$ \\
VO ${ }_{2}$ peak $\left(\mathrm{mL} \cdot \mathrm{kg}^{-1} \cdot \mathrm{min}^{-1}\right)$ & $47.4 \pm 1.9$ & $50.4 \pm 2.6^{*}$ & $46.7 \pm 2.5$ & $46.9 \pm 2.3$ \\
\hline
\end{tabular}

Note. ${ }^{*}$ significantly lower than pre-test value at $\mathrm{p}<0.05,{ }^{* *}$ significantly lower than pre-test value at $\mathrm{p}<0.01,{ }^{*}$ significantly higher than pre-test value at $\mathrm{p}<0.001, \mathrm{BMI}$ : body mass index, FFM: fat free mass, $\Sigma \mathrm{S}$ : sum of the eight skinfolds (biceps, triceps, subscapular, chest, suprailliac, abdominal, thigh, medial calf), Trunk $\Sigma$ S: sum of the trunk skinfolds (subscapular, chest, suprailiac, abdominal), Arm $\Sigma$ S: sum of the arm skinfolds (biceps, triceps), Leg $\Sigma S$ : sum of the leg skinfolds (thigh, medial calf), DBP: diastolic blood pressure, SBP: systolic blood pressure, MAP: mean arterial blood pressure, HR: heart rate, RDpeak: peak running distance during shuttle run test, $\mathrm{VO}_{2}$ peak: estimated peak oxygen consumption from shuttle run test.

Relative to the control group, the soccer group showed a significant improvement in their endurance capacity on the SRT following the weekly intervention period (Table 1). After eight weeks of match-play, in the soccer group, VO2peak $\left(\mathrm{F}_{1,18}=21.743, \mathrm{p}<0.001\right)$ and RDpeak $\left(\mathrm{F}_{1,18}=15.354, \mathrm{p}<0.001\right)$ increased by $6.3 \%$ and $16.4 \%$, 
respectively, whereas in the control group no significant changes were observed in VO2peak or RDpeak $(\mathrm{p}>0.05)$. Moreover, submaximal HR responses also showed a slight tendency to decrease after the intervention period in the soccer group (Table 1$)$, though not significantly ( $\mathrm{p}>0.05)$.

The soccer group showed a significant improvement in its $\mathrm{SJ}\left(\mathrm{F}_{1,18}=8.493, \mathrm{p}<0.01\right)$ and $\mathrm{CMJ}\left(\mathrm{F}_{1.18}=8.089\right.$, $\mathrm{p}<0.05$ ) performance following the weekly intervention period (Table 2). After eight weeks of match-play, in the soccer group, SJ and CMJ heights increased by $9.5 \%$ and $9.1 \%$, respectively, whereas in the control group no significant changes were observed in jump heights. Furthermore, peak and minimum power outputs also showed a slight tendency to increase after the intervention period in the soccer group (Table 2), though not significantly $(\mathrm{p}>0.05)$.

TABLE 2 Anaerobic performance variables and isokinetic strength ratios before and after the 8 weeks of weekly intervention in the soccer and control groups. Data are presented as means $\pm \mathrm{sd}$

\begin{tabular}{lcccc} 
& \multicolumn{2}{c}{ Soccer Group } & \multicolumn{2}{c}{ Control Group } \\
\hline & Pre & Post & Pre & Post \\
\hline Absolute peak power (W) & $561.1 \pm 68.2$ & $577.9 \pm 60.6$ & $614.1 \pm 77.6$ & $609.5 \pm 54.7$ \\
Relative peak power $\left(\mathrm{W} . \mathrm{kg}^{-1}\right)$ & $7.96 \pm 1.1$ & $8.28 \pm 0.8$ & $8.51 \pm 1.1$ & $8.44 \pm 0.7$ \\
Absolute mean power (W) & $416.9 \pm 30.5$ & $411.9 \pm 24.9$ & $430.4 \pm 31.5$ & $436.3 \pm 38.2$ \\
Relative mean power (W.kg $\left.{ }^{-1}\right)$ & $5.90 \pm 0.5$ & $5.91 \pm 0.5$ & $5.96 \pm 0.31$ & $6.03 \pm 0.3$ \\
Absolute min. power (W) & $295.0 \pm 24.2$ & $304.9 \pm 19.5$ & $312.6 \pm 37.5$ & $298.3 \pm 34.2$ \\
Relative min. power (W.kg-1) & $4.19 \pm 0.5$ & $4.38 \pm 0.3$ & $4.32 \pm 0.3$ & $4.12 \pm 0.4$ \\
Fatigue index (\%) & $46.6 \pm 8.7$ & $46.7 \pm 6.5$ & $48.4 \pm 8.4$ & $50.7 \pm 7.1$ \\
SJ (cm) & $47.6 \pm 3.2$ & $52.1 \pm 4.2 * *$ & $47.8 \pm 3.7$ & $48.5 \pm 4.0$ \\
$\mathrm{CMJ}(\mathrm{cm})$ & $49.5 \pm 3.4$ & $54.0 \pm 3.9 *$ & $49.7 \pm 3.8$ & $50.8 \pm 4.5$ \\
$\mathrm{H}_{\text {con }} / \mathrm{Q}_{\text {con }}$ Ratio & $56.87 \pm 5.8$ & $56.61 \pm 6.1$ & $53.99 \pm 5.7$ & $57.21 \pm 3.4$ \\
$\mathrm{H}_{\text {ecc }} / \mathrm{Q}_{\text {con }}$ Ratio & $0.78 \pm 0.1$ & $0.79 \pm 0.1$ & $0.80 \pm 0.1$ & $0.75 \pm 0.1$ \\
\hline
\end{tabular}

Note. ${ }^{*}$ significantly higher than pre-test value at $\mathrm{p}<0.05,{ }^{* *}$ significantly higher than pre-test value at $\mathrm{p}<0.01, \mathrm{SJ}$ : squat jump, CMJ: countermovement jump, $\mathrm{H}_{\text {con }} / \mathrm{Q}_{\text {con }}$ : concentric hamstring/quadriceps, $\mathrm{H}_{\text {ecc }} / \mathrm{Q}_{\text {con }}$ : eccentric hamstring/ concentric quadriceps.

The results indicated that after the training period $\mathrm{Q}_{\text {con }} \mathrm{PT}\left(\mathrm{F}_{1,18}=5.512, \mathrm{p}<0.05\right)$ and $\mathrm{PT} / \mathrm{BW}\left(\mathrm{F}_{1,18}=5.846\right.$, $\mathrm{p}<0.05)$ and $\mathrm{H}_{\text {ecc }} \mathrm{PT}\left(\mathrm{F}_{1,18}=4.588, \mathrm{p}<0.05\right)$ and $\mathrm{PT} / \mathrm{BW}\left(\mathrm{F}_{1,18}=6.064, \mathrm{p}<0.05\right)$ values increased in the soccer group, but no changes were observed in the control group (Figure 2). Furthermore, conventional and dynamic strength control ratios remained the same after eight weeks of interventions in both groups ( $p>0.05)$ (Table 2).
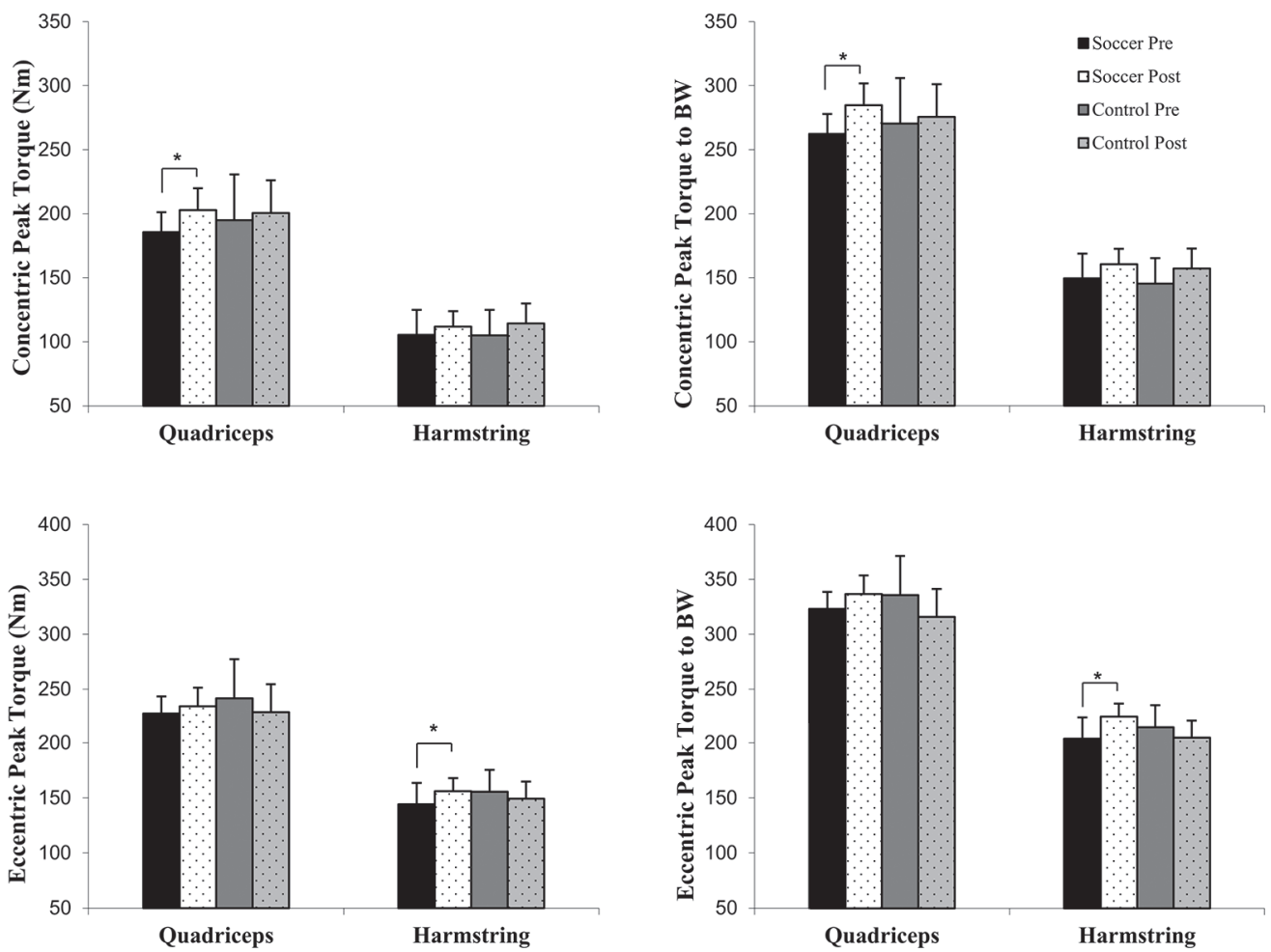

FIGURE 2 Weekly recreational soccer intervention induced changes in isokinetic strength performance over 8 weeks Note. *significantly higher than pre-test values at $p<0.05$ 


\section{Discussion}

This study examined whether once-a-week RS for eight weeks influenced the physical fitness status of sedentary young men. To our knowledge, only one previous study (Beato et al., 2017) has examined the effect of a single one-hour RS intervention a week on the level of physical fitness. However, while Beato et al. (2017) examined the effects of RS on health-related physical fitness components in middle-aged males, the present study focuses on both health- and performance-related physical fitness components in young males. Thus, the main contribution of this study concerning the existing literature is that it provides information about whether the components of health- and performance-related physical fitness of young sedentary individuals are influenced by such a low frequency of soccer activity. The main findings revealed that although eight weeks of one-hour weekly small-sided RS resulted in the improvement of several physical fitness components, including \%BF, aerobic endurance, and muscular strength in sedentary young men, it could not produce sufficient stimulus on resting and submaximal HR responses and blood pressure, which can be considered as an important indicator of cardiovascular health status. In addition, the current study indicated that weekly RS intervention over eight weeks failed to improve anaerobic energy turnover.

A recent review and meta-analysis indicated that small-sided RS with training frequency of two to three sessions per week positively affects aerobic fitness level regardless of the age, sex and health status of the participants (Hammami et al., 2016; Milanovic, Pantelic, Covic, Sporis, \& Krustrup, 2015a). Krustrupt et al. (2009), in a study conducted on healthy untrained males, indicated that $\mathrm{VO}_{2}$ max improved $7 \%$ after two to three weekly one-hour small-sided RS sessions over four weeks, and additional improvements were observed from 4 to 12 weeks. Thus, it can be suggested that the effectiveness of RS on aerobic endurance begins early in the intervention period. Similarly, the present study indicated that there were $16.4 \%$ and $6.3 \%$ increases in RDpeak during the SRT and estimated $\mathrm{VO}_{2}$ peak, respectively. Similar to the present findings, Beato et al. (2017) reported $4.4 \%$ and 5.95\% increase in $\mathrm{VO}_{2}$ max and maximal aerobic speed, respectively, after 12 weeks of weekly performed RS in middle-aged males. These findings recommended that RS is an effective activity to improve aerobic endurance level of participants even performed only once a week. Unfortunately, oxygen consumption could not be determined directly in this study. However, enhanced maximal oxygen consumption may be a plausible suggestion for the increase in aerobic endurance. In fact, the activity profile during small-sided RS is similar to interval training, which is proven to be an effective method for $\mathrm{VO}_{2} \max$ improvement (Milanovic, Sporis, \& Weston, 2015d). Notably, high-intensity periods during RS (time spend over 90\% HRmax) elicits greater improvement in $\mathrm{VO}_{2}$ max compared with aerobic running (Krustrup et al., 2009). The effectiveness of RS on aerobic fitness was also indicated by Randers et al. (2010a) who observed that $\mathrm{VO}_{2}$ max can be maintained over a long time even though the training frequency reduced from 2.4 to 1.3 sessions per week.

It was demonstrated that the untrained males participating in the soccer training programme, two to three times weekly for 12 weeks, each lasting $60 \mathrm{~min}$, had a decrease in resting HR and HR during submaximal continuous running. In addition, in the same study, it was observed that regular soccer training resulted in 8 and $5 \mathrm{mmHg}$ drops of SBP and DBP, respectively. Similar observations were made by Anderson et al. (2010) and Randers et al (2010a) in untrained males when RS was performed two to three weekly over 12 weeks. Beato et al. (2017) also indicated beneficial effects of RS on SBP and MAP performed only once a week. In contrast, the present results showed no-significant decrease in either blood pressure or HR responses at rest and during submaximal exercise after the intervention period. However, the observed decrease of $3.9 \mathrm{mmHg}$ (89.6 vs 85.7) in MAP in this study is in accordance with the findings of Beato et al. (2017) and Randers et al. (2010a) who indicated $3 \mathrm{mmHg}$ and $5 \mathrm{mmHg}$ drops in MAP, respectively, over 12 weeks of football training in untrained males.

In contrast, the extents to which values can be changed by training depend on subjects' levels before the initiation of the training programme. In this study, before the initiation of the intervention period, the SBP, DBP, and resting HR values of our participants were within the normal range or at somewhat lower level (Table 1), which may attenuate the adaptation process. Cornelissen and Fagard (2005), in a random effects model meta-analysis study, indicated that the reduction of SBP and DBP were higher in hypertensive study groups compared with normotensive study groups. Similarly, Krustrup et al. (2009) observed that the reduction of resting blood pressure was more pronounced in the seven subjects with the highest initial values. Randers et al. (2012) also indicated that although blood pressure was unaltered after 12 weeks of street soccer (2.2 per week), DBP was lowered for all participants with previous values greater than $75 \mathrm{mmHg}$. Therefore, future studies may be needed to further examine the effectiveness of weekly RS intervention on blood pressure and HR responses in different populations, especially including those who are hypertensive and who have initially high resting HR values.

According to the present results, the sum of eight skinfolds and \%BF only slightly decreased in the soccer group after the intervention period, but no significant changes were observed in BM, BMI, or FFM. In agreement with the present results, a recent study demonstrated that once-a-week $1 \mathrm{~h}$ performed RS would not produce substantial and significant improvements in body weight, \%BF, and BMI in middle-aged males (Beato et al., 2017). The findings of these two studies can be interpreted as once a week RS intervention is not a proper strategy when the major aim of participants is to reduce body weight and $\% \mathrm{BF}$. However, a previous study conducted on young adult men revealed that 12 weeks of three $60 \mathrm{~min}$ soccer sessions per week led 
to considerable decrease on BM, BMI, and \%BF (Milanovic et al., 2015b). Similarly, a recent meta-analysis concluded that two weekly 60 min RS interventions lasting 12-16 weeks are likely to cause a decrease in total fat mass of 1-3 kg (Milanovic et al., 2018). In addition, it was demonstrated that RS intervention can increase lean body mass when performed two to three times weekly over 12 weeks in untrained males and females (Krustrup et al., 2009; Krustrup et al., 2010a; Krustrup et al., 2010b). Therefore, it seems that the effect of RS activity on body composition is unsurprisingly related to the frequency of weekly sessions/total volume and length of the intervention period.

Previous studies investigating the effectiveness of RS on the neuromuscular system showed that this type of activity potentially increases muscular strength when the exercise is performed two to three times weekly over 12 weeks, or for longer periods of time (Krustrup et al., 2009; Krustrup et al., 2010a; Krustrup et al., 2010b). In a study of young men participating in RS two to three times a week over 12 weeks, Krustrup et al. (2010a) observed a significant increase in the quadriceps muscle mass, mean fibre area, lean body mass as well as maximal isometric hamstring strength. Moreover, a recent meta-analysis indicated a positive effect of RS on muscular fitness evaluated as jump performance (Milanovic et al., 2018). Similarly, according to the present results, the soccer group increased their $\mathrm{Q}_{\text {con }}, \mathrm{H}_{\text {ecc }}$ strength and jumping performances after the intervention period. Indeed, the soccer practice involves intermittent physical activity and variety of skills requiring running, sprinting, jumping and kicking. All these activity patterns are the quadriceps-dominant activities while the hamstring plays an important role in the stability of the knee joint complex (Fried \& Lloyd, 1992). Furthermore, the hamstring muscles contract eccentrically during soccer activities, such as kicking, sprinting or changing of directions, in order to decelerate the forward movement of the leg. Therefore, improvements in $\mathrm{Q}_{\text {con }}$ and $\mathrm{H}_{\text {ecc }}$ strength could be explained by the contraction characteristics of muscle groups during soccer activities. However, because of the lack of increase in FFM observed in this study, it is more likely that the strength gains may associate with an increase in neural recruitment rather than muscular hypertrophy.

The present results also showed that conventional and functional strength ratio evaluations did not differ after an eight-week intervention period. The conventional ratio has been claimed to be one of the many variables that contribute to knee joint stability and control (Aagaard, Simonsen, Magnusson, Larson, \& Dyhre-Poulsen, 1998; Kellis \& Baltzopoulus, 1998). The practical significance of the functional ratio is related with the functional tasks (i.e., vertical jump) or dynamic knee joint movements (Coombs \& Garbutt, 2002). Although there were significant increases in $\mathrm{Q}_{\text {con }}$ and $\mathrm{H}_{\text {ecc }}$ strength after the intervention period, the symmetric strength improvement repressed the development of the functional strength ratio. In this study, it is also apparent that symmetric strength gains functionally resulted in significant improvement in vertical jump performances (Table 2). These findings indicated that weekly soccer practice also had a beneficial effect on functional movement tasks. However, the amount of increase in jumping performance observed in this study $(9.1-9.5 \%$, for CMJ and SJ, respectively) is lower compared to that in the study of Milanovic et al. (2015c). (12.1-14.8\% for $\mathrm{CMJ}$ and SJ, respectively) where training performed three times a week for 12 weeks.

In conclusion, once-a-week RS interventions over eight weeks positively influenced the physical fitness level of sedentary young men by lowering $\% \mathrm{BF}$ and increasing aerobic endurance, jumping performance, $\mathrm{Q}_{\text {con }}$ and $\mathrm{H}_{\text {ecc }}$ strengths. In contrast, it could not produce sufficient stimulus to decrease resting and submaximal $\mathrm{HR}$, blood pressures, anaerobic performance, $\mathrm{Q}_{\mathrm{ecc}}$ and $\mathrm{H}_{\text {con }}$ strengths. However, the participants of this study were already physically fit healthy young subjects and the intervention duration somewhat lower than the previous studies. Therefore, remarkable initial values in combination with a relatively short intervention period might resulted in an attenuated adaptation response. Nonetheless, even though the present findings recommended that RS performed once a week provides substantial improvement in aerobic endurance and leg strength parameters, the participants who wish to further improve their health and performance levels should increase the weekly frequency of RS activity. Since the magnitude of adaptations can be influenced by several factors, including age, gender, and health status (Milanovic et al., 2018), the findings of this study cannot easily be extended to other populations. Therefore, future studies are needed to examine the health and performance effects of single RS a week in a diverse population.

\section{REFERENCES}

Aagaard, P., Simonsen, E. B., Magnusson, S. P., Larsson, B., \& Dyhre-Poulsen, P. (1998). A new concept for isokinetic hamstring: quadriceps muscle strength ratio. The American journal of Sports Medicine, 26(2), 231-237. doi: org/10.1177/03635465980260021201

Andersen, L. J., Randers, M. B., Westh, K., Martone, D., Hansen, P. R., Junge, A., ... \& Krustrup, P. (2010). Football as a treatment for hypertension in untrained 30-55-year-old men: a prospective randomized study. Scandinavian Journal of Medicine \& Science in Sports, 20, 98-102. doi: org/10.1111/j.16000838.2010.01109.x

Aslan, A. (2013). Cardiovascular responses, perceived exertion and technical actions during small-sided recreational soccer: Effects of pitch size and number of players. Journal of Human Kinetics, 38, 95-105. doi: org/10.2478/hukin-2013-0049

Beato, M., Impellizzeri, F. M., Coratella, G., \& Schena, F. (2016). Quantification of energy expenditure of recreational football. Journal of Sports Sciences, 34(24), 2185-2188. doi: org/10.1080/02640414.2016.1167280

Beato, M., Coratella, G., Schena, F., \& Impellizzeri, F. M. (2017). Effects of recreational football performed 
once a week ( $1 \mathrm{~h}$ per 12 weeks) on cardiovascular risk factors in middle-aged sedentary men. Science and Medicine in Football, 1(2), 171-177. doi: org/10.1080/24733938.2017.1325966

Biodex Multi-Joint System Pro (2017). Setup/Operation Manual. Retrieved 07/02, 2017, from: http://www. biodex.com

Coombs, R., \& Garbutt, G. (2002). Developments in the use of the hamstring/quadriceps ratio for the assessment of muscle balance. Journal of Sports Science \& Medicine, 1(3), 56-62.

Cornelissen, V. A., \& Fagard, R. H. (2005). Effects of endurance training on blood pressure, blood pressureregulating mechanisms, and cardiovascular risk factors. Hypertension, 46(4), 667-675. doi: 10.1161/01. HYP.0000184225.05629.51

Dellal, A., Owen, A., Wong, D. P., Krustrup, P., van Exsel, M., \& Mallo, J. (2012). Technical and physical demands of small vs. large sided games in relation to playing position in elite soccer. Human Movement Science, 31(4), 957-969. doi: org/10.1016/j.humov.2011.08.013

Elliott, K. J., Sale, C., \& Cable, N. T. (2002). Effects of resistance training and detraining on muscle strength and blood lipid profiles in postmenopausal women. British Journal of Sports Medicine, 36(5), 340-344. doi: org/10.1136/bjsm.36.5.340

Faulkner, J. A. (1968). Physiology of swimming and diving. In F. H. (Ed.), Exercise physiology. Baltimore: Academic Press.

Fried, T., \& Lloyd, G. J. (1992). An overview of common soccer injuries, management and prevention. Sports Medicine, 14, 269-275. doi: org/10.2165/00007256-199214040-00005

Gibala, M. J., Little, J. P., MacDonald, M. J., \& Hawley, J. A. (2012). Physiological adaptations to low-volume, high-intensity interval training in health and disease. The Journal of Physiology, 590(5), 1077-1084. doi: org/10.1113/jphysiol.2011.224725

Hammami, A., Chamari, K., Slimani, M., Shephard, R. J., Yousfi, N., Tabka, Z., \& Bouhlel, E. (2016). Effects of recreational soccer on physical fitness and health indices in sedentary healthy and unhealthy subjects. Biology of Sport, 33(2), 127-137. doi: 10.5604/20831862.1198209

Hiruntrakul, A., Nanagara, R., Emasithi, A., \& Borer, K. T. (2011). Effect of once a week endurance exercise on fitness status in sedentary subjects. Journal of the Medical Association of Thailand, 93(9), 1070-1074.

Inbar, O., Bar-Or, O., Skinner, J. S. (1996). The Wingate Anaerobic Test. Human Kinetics, Champaign, IL.

Karvonen, M. J. (1957). The effects of training on heart rate: a longitudinal study. Ann Med Exp Biol Fenn, 35, 307-315.

Kellis, E., \& Baltzopoulos, V. (1998). Muscle activation differences between eccentric and concentric isokinetic exercise. Medicine and Science in Sports and Exercise, 30(11), 1616-1623. doi: 10.1097/00005768199811000-00010

Krustrup, P., Nielsen, J. J., Krustrup, B., Christensen, J. F., Pedersen, H., Randers, M. B., ...\& Bangsbo, J. (2009). Recreational soccer is an effective health promoting activity for untrained men. British Journal of Sports Medicine, 43, 825-831. doi: org/10.1136/bjsm.2008.053124

Krustrup, P., Christensen, J. F., Randers, M. B., Pedersen, H., Sundstrup, E., Jakobsen, M. D., ... \& Bangsbo, J. (2010a). Muscle adaptations and performance enhancements of soccer training for untrained men. European Journal of Applied Physiology, 108(6), 1247-1258. doi: org/10.1007/s00421-009-1319-8

Krustrup, P., Hansen, P. R., Andersen, L. J., Jakobsen, M. D., Sundstrup, E., Randers, M. B., ... \& Junge, A. (2010b). Long-term musculoskeletal and cardiac health effects of recreational football and running for premenopausal women. Scandinavian Journal of Medicine \& Science in Sports, 20, 58-71. doi: org/10.1111/ j.1600-0838.2010.01111.x

Krustrup, P., Hansen, P. R., Nielsen, C. M., Larsen, M. N., Randers, M. B., Manniche, V., ... \& Bangsbo, J. (2014). Structural and functional cardiac adaptations to a 10-week school-based football intervention for 9-10-year-old children. Scandinavian Journal of Medicine \& Science in Sports, 24, 4-9. doi: org/10.1111/ sms. 12277

Leger, L. A., Mercier, D., Gadoury, C., \& Lambert, J. (1988). The multistage 20 metre shuttle run test for aerobic fitness. Journal of Sports Sciences, 6(2), 93-101. doi: org/10.1080/02640418808729800

Lohman, T. G., \& Roche, A. F. (1988). Anthropometric standardization reference manual (Vol. 177, pp. 3-8). R. Martorell (Ed.). Champaign: Human kinetics books.

Matsuzaka, A., Takahashi, Y., Yamazoe, M., Kumakura, N., Ikeda, A., Wilk, B., \& Bar-Or, O. (2004). Validity of the multistage 20-m shuttle-run test for Japanese children, adolescents, and adults. Pediatric Exercise Science, 16(2), 113-125. doi: org/10.1123/pes.16.2.113

Milanovic, Z., Pantelic, S., Covic, N., Sporis, G., Krustrup, P. (2015a). Is recreational soccer effective for improving $\mathrm{VO}_{2}$ max? A systematic review and meta-analysis. Sports Medicine, 45(9), 1339-1353. doi: org/10.1007/s40279-015-0361-4

Milanović, Z., Pantelić, S., Kostić, R., Trajković, N., \& Sporiš, G. (2015b). Soccer vs. running training effects in young adult men: which programme is more effective in improvement of body composition? Randomized controlled trial. Biology of Sport, 32(4), 301-305. doi: 10.5604/20831862.1163693

Milanović, Z., Pantelić, S., Sporiš, G., Mohr, M., \& Krustrup, P. (2015c). Health-related physical fitness in healthy untrained men: effects on VO2max, jump performance and flexibility of soccer and moderate-intensity continuous running. PloS one, 10(8), e0135319. doi: org/10.1371/journal.pone.0135319

Milanović, Z., Sporiš, G., \& Weston, M. (2015d). Effectiveness of high-intensity interval training (HIT) and continuous endurance training for VO 2 max improvements: a systematic review and meta-analysis of 
controlled trials. Sports Medicine, 45(10), 1469-1481. doi: org/10.1007/s40279-015-0365-0

Milanović, Z., Pantelić, S., Čović, N., Sporiš, G., Mohr, M., \& Krustrup, P. (2018). Broad-spectrum physical fitness benefits of recreational football: a systematic review and meta-analysis. British Journal of Sports Medicine, 43,825-831. doi: 10.1136/bjsports-2017-097885

Randers, M. B., Nielsen, J. J., Krustrup, B. R., Sundstrup, E., Jakobsen, M. D., Nybo, L., ... \& Krustrup, P. (2010a). Positive performance and health effects of a football training program over 12 weeks can be maintained over a 1-year period with reduced training frequency. Scandinavian Journal of Medicine \& Science in Sports, 20, 80-89. doi: org/10.1111/j.1600-0838.2010.01091.x

Randers, M. B., Nybo, L., Petersen, J., Nielsen, J. J., Christiansen, L., Bendiksen, M., ... \& Krustrup, P. (2010b). Activity profile and physiological response to football training for untrained males and females, elderly and youngsters: influence of the number of players. Scandinavian Journal of Medicine \& Science in Sports, 20, 14-23. doi: org/10.1111/j.1600-0838.2010.01069.x

Randers, M. B., Petersen, J., Andersen, L. J., Krustrup, B. R., Hornstrup, T., Nielsen, J. J., ... \& Krustrup, P. (2012). Short-term street soccer improves fitness and cardiovascular health status of homeless men. European Journal of Applied Physiology, 112(6), 2097-2106. doi: org/10.1007/s00421-011-2171-1

Winett, R. A., \& Carpinelli, R. N. (2000). Examining the validity of exercise guidelines for the prevention of morbidity and all-cause mortality. Annals of Behavioral Medicine, 22(3), 237-245. doi: org/10.1007/ BF02895119 